\title{
Low dose chloroquine decreases insulin resistance in human metabolic syndrome but does not reduce carotid intima-media thickness
}

Janet B. McGill ${ }^{1 *+}$ CD, Mariko Johnson ${ }^{1 \dagger}$, Stacy Hurst ${ }^{1}$, William T. Cade ${ }^{2}$, Kevin E. Yarasheski ${ }^{1}$, Richard E. Ostlund ${ }^{1}$, Kenneth B. Schechtman ${ }^{3}$, Babak Razani ${ }^{4}$, Michael B. Kastan ${ }^{5}$, Donald A. McClain ${ }^{6}$, Lisa de las Fuentes ${ }^{4}$, Victor G. Davila-Roman ${ }^{4}$, Daniel S. Ory ${ }^{4}$, Samuel A. Wickline ${ }^{4}$ and Clay F. Semenkovich ${ }^{1,7^{*}}$

\begin{abstract}
Background: Metabolic syndrome, an obesity-related condition associated with insulin resistance and low-grade inflammation, leads to diabetes, cardiovascular diseases, cancer, osteoarthritis, and other disorders. Optimal therapy is unknown. The antimalarial drug chloroquine activates the kinase ataxia telangiectasia mutated (ATM), improves metabolic syndrome and reduces atherosclerosis in mice. To translate this observation to humans, we conducted two clinical trials of chloroquine in people with the metabolic syndrome.

Methods: Eligibility included adults with at least 3 criteria of metabolic syndrome but who did not have diabetes. Subjects were studied in the setting of a single academic health center. The specific hypothesis: chloroquine improves insulin sensitivity and decreases atherosclerosis. In Trial 1, the intervention was chloroquine dose escalations in 3-week intervals followed by hyperinsulinemic euglycemic clamps. Trial 2 was a parallel design randomized clinical trial, and the intervention was chloroquine, $80 \mathrm{mg} /$ day, or placebo for 1 year. The primary outcomes were clamp determinedinsulin sensitivity for Trial 1, and carotid intima-media thickness (CIMT) for Trial 2. For Trial 2, subjects were allocated based on a randomization sequence using a protocol in blocks of 8. Participants, care givers, and those assessing outcomes were blinded to group assignment.
\end{abstract}

Results: For Trial 1,25 patients were studied. Chloroquine increased hepatic insulin sensitivity without affecting glucose disposal, and improved serum lipids. For Trial 2, 116 patients were randomized, 59 to chloroquine (56 analyzed) and 57 to placebo (51 analyzed). Chloroquine had no effect on CIMT or carotid contrast enhancement by MRI, a pre-specified secondary outcome. The pre-specified secondary outcomes of blood pressure, lipids, and activation of JNK (a stress kinase implicated in diabetes and atherosclerosis) were decreased by chloroquine. Adverse events were similar between groups.

Conclusions: These findings suggest that low dose chloroquine, which improves the metabolic syndrome through ATM-dependent mechanisms in mice, modestly improves components of the metabolic syndrome in humans but is unlikely to be clinically useful in this setting.

Trial registration ClinicalTrials.gov (NCT00455325, NCT00455403), both posted 03 April 2007

\footnotetext{
*Correspondence: jmcgill@wustl.edu; csemenko@wustl.edu

${ }^{\dagger}$ Janet B. McGill and Mariko Johnson contributed equally to this work

${ }^{1}$ Division of Endocrinology, Metabolism \& Lipid Research, Department

of Medicine, Washington University School of Medicine, 660 South Euclid

Avenue, Box 8127, St. Louis, MO 63110, USA

Full list of author information is available at the end of the article
} 
Keywords: Chloroquine, Metabolic syndrome, Carotid intima-media thickness, Insulin sensitivity, Glucose disposal, Atheroma, Blood pressure, Lipids, JNK

\section{Introduction}

A combination of increased triglycerides, low HDL cholesterol, hypertension, above normal fasting glucose, and increased waist circumference constitutes the metabolic syndrome [1], which predisposes to diabetes, cardiovascular disease, and all-cause mortality [2]. Current therapy is directed at individual components of the syndrome, which are related to insulin resistance. Obesity-related insulin resistance is associated with low-grade systemic inflammation characterized by increased activation of a stress kinase known to induce insulin resistance, c-Jun $\mathrm{N}$-terminal kinase (JNK) [3]. Pronounced weight loss is associated with decreased cardiovascular events [4], but there are other causes of insulin resistance besides obesity that could provide insight into relationships between insulin resistance and cardiovascular disease. DNA damage disorders including Hutchinson-Gilford progeria, Werner syndrome, Cockayne syndrome, and ataxia telangiectasia are associated with insulin resistance and vascular disease [5]. Mice deficient in ataxia telangiectasia mutated (ATM), the kinase mutated in ataxia telangiectasia, have increased activation of JNK in macrophages, insulin resistance, hypertension, and increased atherosclerosis [6-8]. ATM activation by the anti-malarial drug chloroquine decreases macrophage JNK activation, blood pressure, insulin resistance, and atherosclerosis in mice $[6,9]$.

Since the ATM axis is associated with altered hepatic insulin sensitivity and atherosclerosis in mice, we translated these rodent data to humans with metabolic syndrome in two exploratory clinical trials: (1) A dose escalation study with a primary endpoint of insulin sensitivity and pre-specified secondary endpoints including serum lipids and blood pressure; and (2) Placebo or chloroquine treatment for 1 year with a primary endpoint of carotid intima-media thickness, a noninvasive predictor of cardiovascular events [10]. The 1 year study utilized the lowest dose associated with improved insulin sensitivity in the dose escalation study and included pre-specified secondary endpoints such as carotid MRI, activation of JNK in isolated monocytes, serum lipids, and blood pressure.

\section{Subjects and methods}

\section{Subjects and trial design}

These single center studies were approved by the Washington University Human Research Protection Office. All subjects gave informed consent and were compensated for their participation. A data safety and monitoring board convened by the National Heart, Lung and Blood Institute (NHLBI) supervised the trials.

For both the dose escalation and double blind trials, inclusion criteria included men and women of any ethnic group between the ages of 18-60 (Trial 1), and 18-70 (Trial 2) (the difference in age between protocols was intended to make the randomized trial more pertinent to a broader age group) who had at least 3 of the components of the metabolic syndrome: elevated fasting triglycerides $(\geq 1.69 \mathrm{mmol} / \mathrm{L})$; low $\mathrm{HDL}$ cholesterol $(<1.29 \mathrm{mmol} / \mathrm{L}$ in women, $<1.03 \mathrm{mmol} / \mathrm{L}$ in men); hypertension $(\geq 130 / 85 \mathrm{~mm} \mathrm{Hg} \leq 160 / 100 \mathrm{mmHg})$ untreated, or hypertension controlled $(\leq 150 / 90 \mathrm{~mm} \mathrm{Hg}$ ) on a stable medication regimen; increased waist circumference ( $>89 \mathrm{~cm}$ in women, $>102 \mathrm{~cm}$ in men); elevated fasting glucose $(\geq 5.6 \mathrm{mmol} / \mathrm{L}$ and $<7.0 \mathrm{mmol} / \mathrm{L})$. For a diagnosis of hypertension, measurements were repeated on two separate days. Fasting glucose was also repeated on two separate days. Fasting lipids were performed once before enrollment but repeated throughout the interventions.

Exclusion criteria were extensive and included: known prior treatment with chloroquine or hydroxychloroquine, $\mathrm{BMI}>45 \mathrm{~kg} / \mathrm{m}^{2}$, coronary artery disease or other vascular disease, history of stroke, eGFR (estimated glomerular filtration rate) $<60 \mathrm{ml} / \mathrm{min} / 1.73 \mathrm{~m}^{2}$, diabetes, seizure disorder, history of psoriasis, hematological disorders (including anemia), current malignancy, asthma or COPD (chronic obstructive pulmonary disease), liver disease (including transaminases $>2 \times$ upper limit of normal), active infection (including HIV-human immunodeficiency virus), any serious illness requiring ongoing medical care, major psychiatric illness, lipid lowering medications (other than statins and $<1 \mathrm{~g}$ daily fish oils), severe hypertension at baseline or taking more than three antihypertensives, use of cimetidine or vitamin $\mathrm{E}$, pregnancy or lactation or intention to become pregnant, inadequate use of contraception, glucose-6-phosphate dehydrogenase deficiency, auditory disease or hearing loss, retinal disease (especially presence of drusen or pigmentary changes at the macula), and any ocular disease interfering with the ability to rigorously assess the retina.

A CONSORT statement flow diagram for the first trial is shown in Fig. 1. The study design for the first trial is shown in Fig. 2a. One hundred forty-four subjects were screened for participation in Trial 1 and 35 individuals with the metabolic syndrome qualified. Twenty-five subjects completed the protocol. Ten discontinued the study 


\section{Dose Escalation}

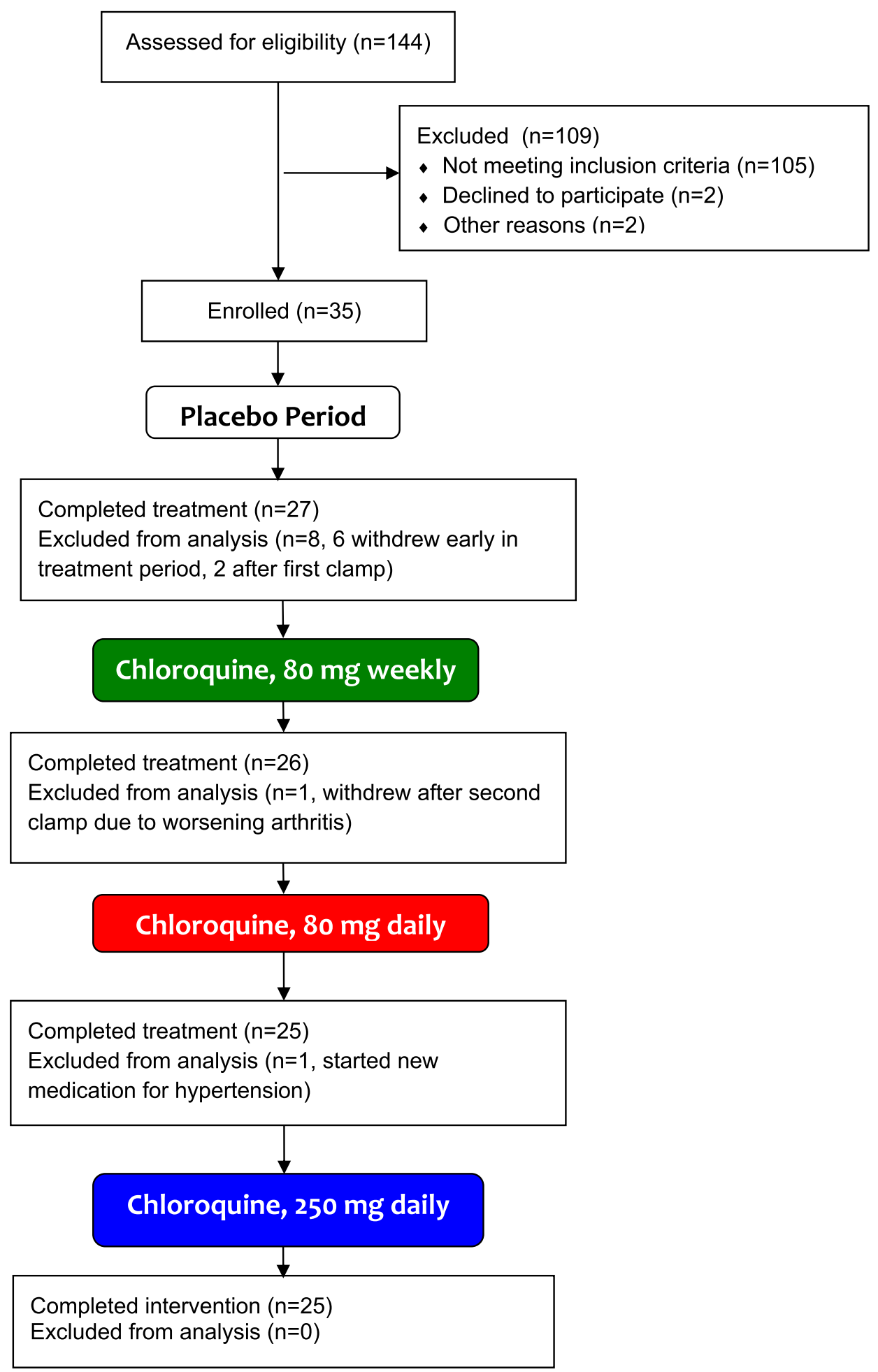

Fig. 1 CONSORT statement flow diagram for subjects in dose escalation study 


\section{(See figure on next page.)}

Fig. 2 Chloroquine dose escalation trial design and results for hyperinsulinemic-euglycemic clamping and lipids. a Diagram of the dose escalation protocol. A 5-7 week washout period was required between limbs to allow for hematologic recovery following the blood drawing associated with clamps. b Glucose disposal rates expressed as $\mu \mathrm{mol}$ glucose $/ \mathrm{kg}$ body weight $/ \mathrm{min}$. Insulin infusion rates were $0,56,181$, or $486 \mathrm{pmol} / \mathrm{m} 2 / \mathrm{min}$. c Hepatic glucose production expressed as ( $\mu \mathrm{mol}$ glucose/kg body weight $/ \mathrm{min}$ ) per pmol/L insulin. d Hepatic insulin sensitivity expressed as percent suppression of glucose production at $56 \mathrm{pmol} / \mathrm{m}^{2} / \mathrm{min}$. e Total, non-HDL, and LDL cholesterol at the end of each limb. f Triglycerides and HDL cholesterol at the end of each limb. Data represent mean \pm SE. ${ }^{*} \mathrm{P}<0.05$ by Tukey's test for multiple comparisons after repeated measures ANOVA

for reasons that included: starting a new medication during the protocol [3], new diagnosis of diabetes during the protocol [1], difficult IV access [1], worsening joint symptoms [1], and miscellaneous issues unrelated to the protocol (such as relocation, 4). For this single blind, placebo-controlled study, each subject took a capsule that was identical in appearance for 21 days. For the first limb, capsule contents were inert. For the second limb, three of the 21 capsules (administered at weekly intervals) contained $80 \mathrm{mg}$ of chloroquine and the remaining capsules were inert. For the third and fourth limbs, capsules contained 80 or $250 \mathrm{mg}$ of chloroquine, respectively. Each limb was separated by a washout period to allow recovery from the blood drawing of the clamp procedure. It was not possible to randomize limb order due to the extremely long half-life of chloroquine; ingestion during an early limb would be associated with tissue levels of the drug and its metabolites during a later placebo limb.

A CONSORT statement flow diagram for the second trial is shown in Fig. 3. The study design for the second trial is shown in Fig. 4a. The blind was held by a research pharmacist, who provided the randomization sequence to the blinded research nurses or physicians who enrolled participants and assigned interventions that included study medications that were identical in appearance. Three hundred fifty-seven subjects were screened for participation in Trial 2 and 155 non-diabetic individuals with metabolic syndrome qualified at the initial screening visit. Of these, 21 withdrew consent before the second screening visit, 4 withdrew consent after the second screening visit and 14 did not qualify for randomization due to abnormal eye exams [4], abnormal carotid imaging [2], anemia [3], G6PD deficiency [2], abnormal liver function tests [2], and psoriasis [1]. The remaining 116 subjects were randomized to placebo or chloroquine. Of those randomized, 19 assigned to placebo and 20 assigned to chloroquine were being treated for hypertension, and were taking $1.3 \pm 1.1$ and $1.1 \pm 1.0$ antihypertensive medications respectively. 15 subjects in each group were taking a statin.

\section{Hyperinsulinemic-euglycemic clamp procedure}

At the end of each limb depicted in Fig. 2a, subjects presented after an overnight fast. The antecubital vein was catheterized for infusion of insulin, glucose and tracer solutions, a hand vein was catheterized for blood sampling, and the hand was maintained in a hotbox at $\sim 55^{\circ} \mathrm{C}$ to arterialize venous sampling. Baseline samples were obtained prior to initiating infusions.

Insulin sensitivity was assayed using a two-step euglycemic clamp technique as described previously [11]. The stable isotope $\left[6,6-{ }^{2} \mathrm{H}_{2}\right]$ glucose $(22 \mu \mathrm{mol} / \mathrm{kg}$ prime and $0.25 \mu \mathrm{mol} / \mathrm{kg} / \mathrm{min}$ constant infusion) was infused during a $90 \mathrm{~min}$ basal period (to allow isotope equilibration) and then continued throughout each study. Plasma glucose was measured at 5-10 min intervals following the basal period. Insulin was initially infused in two stages consisting of rates of 181 and $486 \mathrm{pmol} / \mathrm{m}^{2} / \mathrm{min}$, but after analyzing results from the first 7 patients, the protocol was modified to include two stages consisting of insulin infusion rates of 56 and $181 \mathrm{pmol} / \mathrm{m}^{2} / \mathrm{min}$ in order to avoid nearly complete suppression of hepatic glucose production at higher insulin infusion rates. Twenty \% dextrose (containing 1.5\% [6,6- $\left.{ }^{2} \mathrm{H}_{2}\right]$ glucose) was infused to maintain blood glucose at $5.00 \mathrm{mmol} / \mathrm{L}$ for $\sim 2 \mathrm{~h}$ at each stage. Plasma was assayed for $6,6{ }^{2} \mathrm{H}_{2}$-glucose enrichment by mass spectrometry. Glucose kinetics were determined using samples obtained at $10 \mathrm{~min}$ intervals during the last $30 \mathrm{~min}$ of the basal period and during each stage of the clamp.

\section{Glucose tolerance testing and assays of serum or plasma}

Oral glucose tolerance testing was performed by administering $75 \mathrm{~g}$ of glucose followed by sampling at 0,30 , 60, 90 and $120 \mathrm{~min}$. Samples were assayed for glucose, insulin, $C$ peptide, and glucagon. AUC calculations were performed using the trapezoid rule for approximating integrals. Lipids, lipoproteins, serum chemistries, and blood counts were assayed by the Washington University Core Laboratory for Clinical Studies, which is CLIA-certified. Since this project addressed the effects of chloroquine on insulin resistance, the cause of which remains obscure, the laboratory also performed exploratory measurements of putative metabolic mediators that have been implicated in insulin resistance and/or its vascular complications [12-16]. These included adiponectin, leptin, iron, VEGF (vascular endothelial growth factor), and IL-17A. Samples for adiponectin and iron studies were assayed at the University of Utah [17]. 


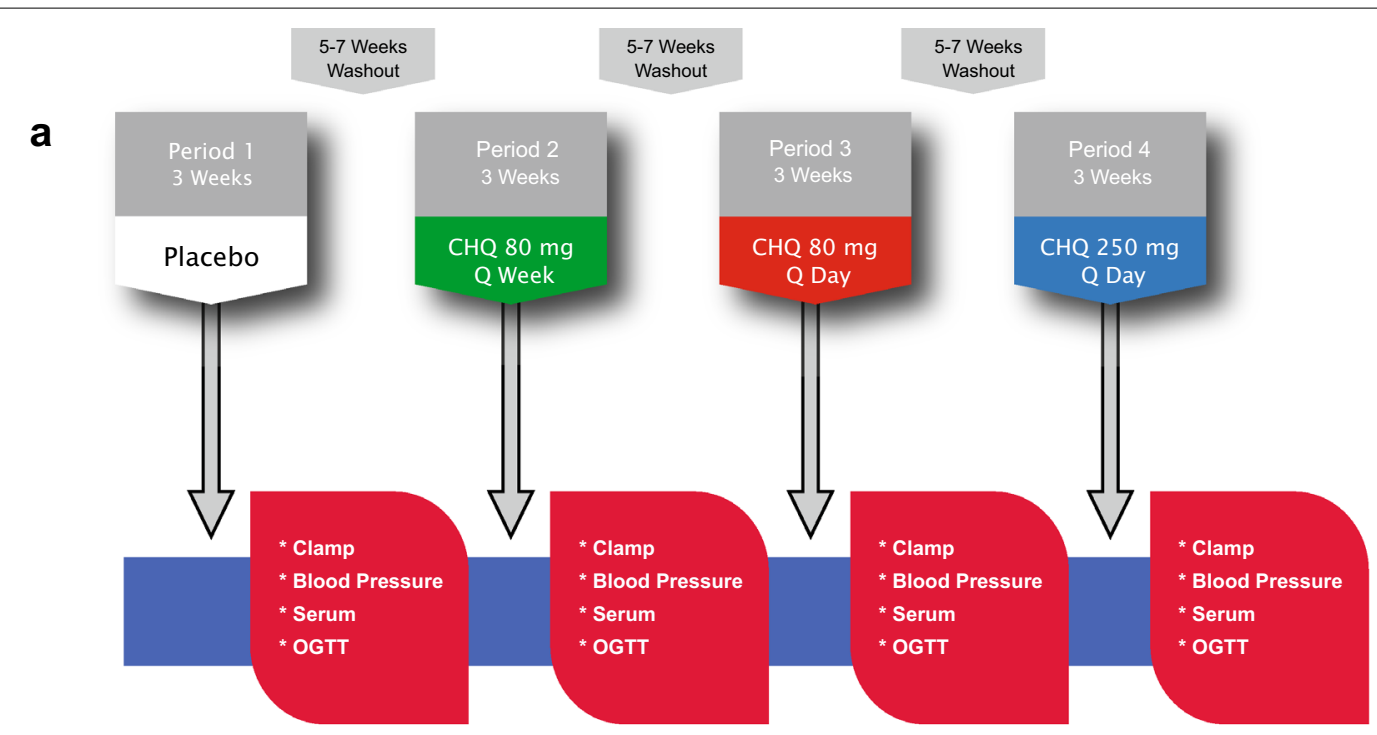

b

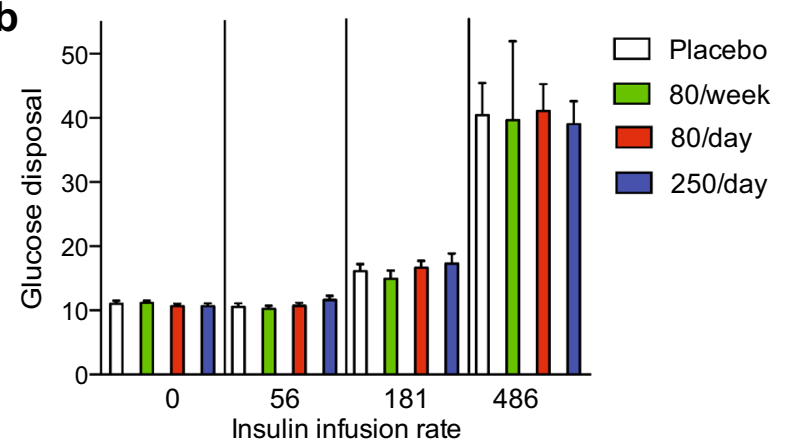

C
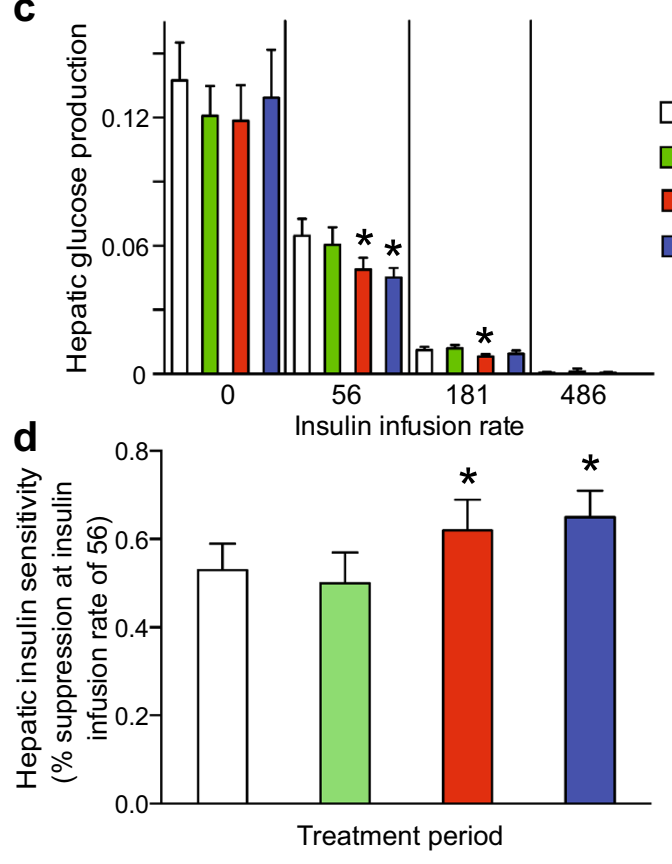
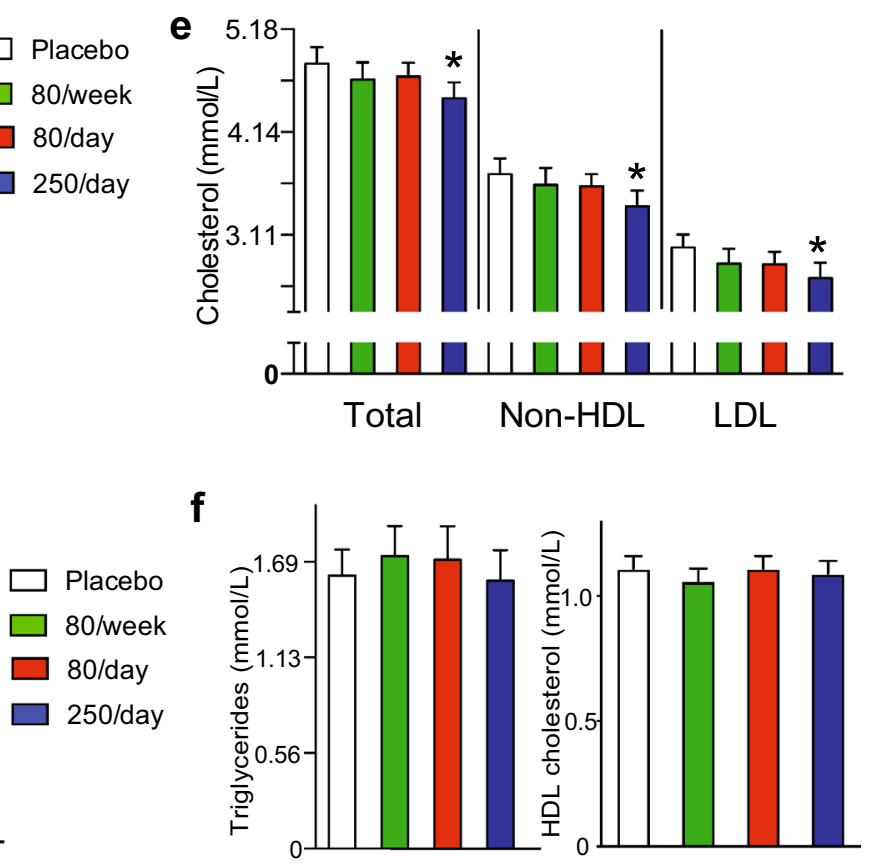


\section{Yearlong Intervention}

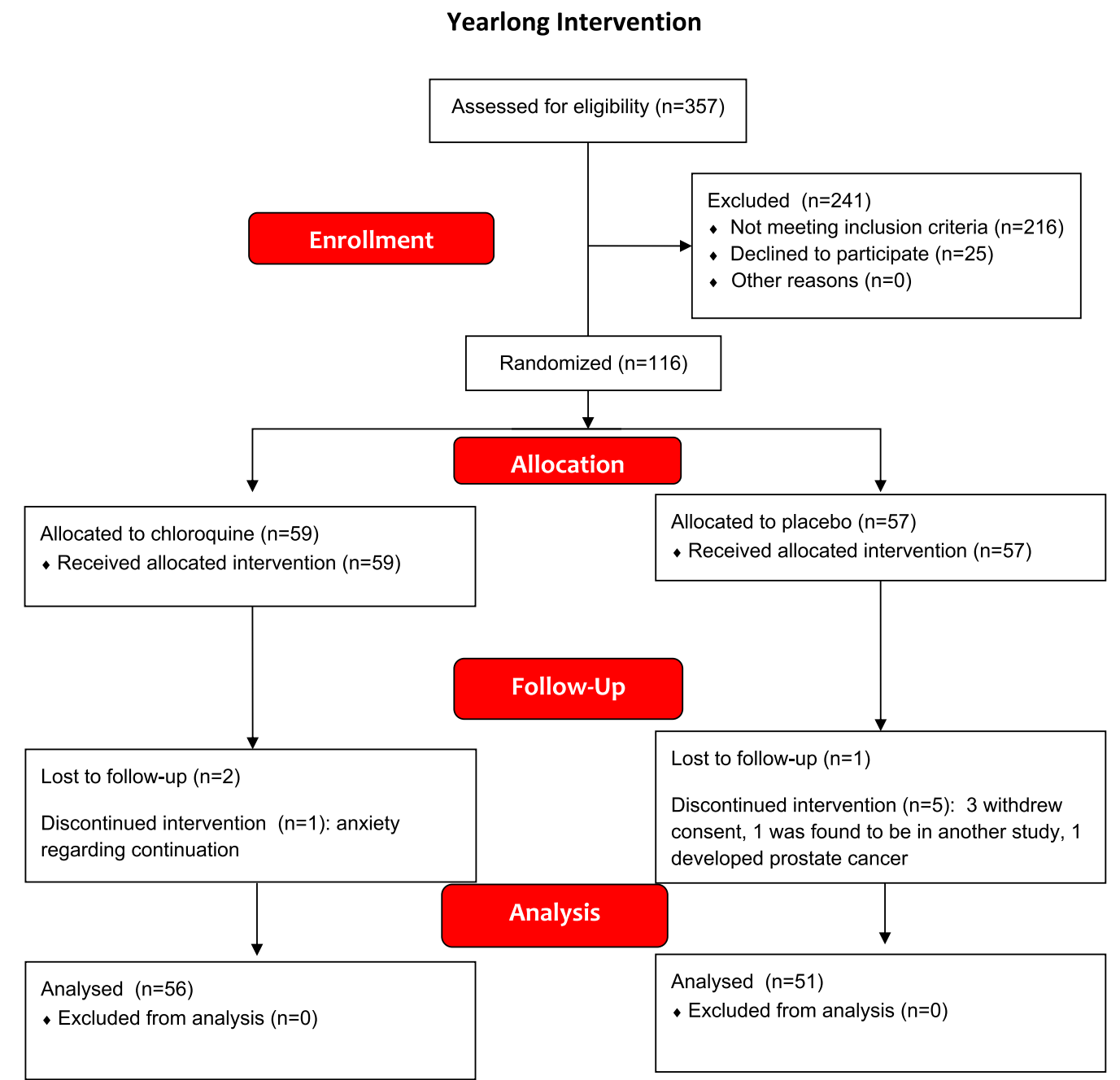

Fig. 3 CONSORT statement flow diagram for subjects in the yearlong randomized clinical trial

\section{Blood pressure determinations}

Two techniques were employed: auscultation of seated subjects at rest was performed by a trained observer who recorded the first and fifth phases of the Korotkoff sounds; and, a portable oscillometric device (SpaceLabs Medical) recorded results every 20 min during the day and every $h$ during the night then data were analyzed as mean values over $24 \mathrm{~h}$, between 0800 and 2200 (daytime), and between 2200 and 0800 (nighttime).

\section{CIMT assessments}

Carotid artery intima-media thickness (CIMT) was measured from B-mode images by a single sonographer using standard approaches $[18,19]$. The average of 3 measurements of the posterior wall of each common carotid $\sim 1 \mathrm{~cm}$ proximal to the carotid bulb was determined; plaques (wall thickening $>50 \%$ of the surrounding wall) were excluded. To establish reproducibility, $10 \%$ of the images were randomly selected and re-measured in a blinded fashion by two independent observers. Intraobserver and inter-observer correlation coefficients were 0.900 and 0.992 .

\section{MRI assessments}

A contouring tool on the Philips ViewForum workstation was used to outline the inner and outer common carotid artery wall regions (right and left) in the first frame immediately below the bifurcation in the T2-weighted image, then areas and diameters of the vessel wall and lumen were calculated. The maximum thickness of the common carotid in the same frame was measured with the line tool. Similar measurements were made for the internal carotid artery in a slice just beyond the bifurcation. For common carotid artery wall contrast enhancement, which represents gadolinium leakage and late hyper enhancement, pre- and post-injection T1 


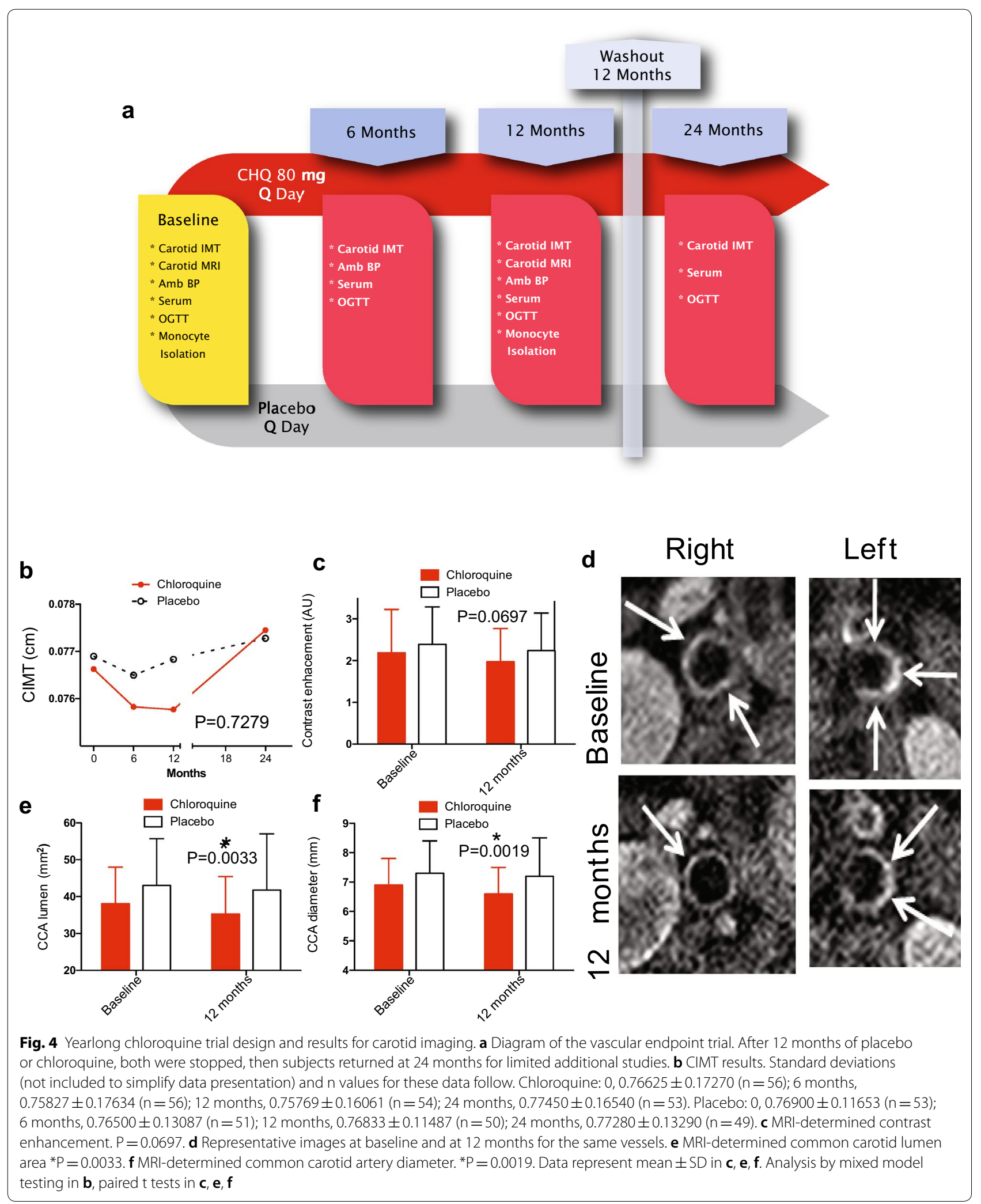


weighted images were compared by dividing the artery into quadrants. The slice nearest the bifurcation manifesting the greatest signal in terms of numbers of quadrants enhanced was chosen by visual comparison with the same pre-injection slice. If the pre-injection signal in the carotid wall appeared bright in any quadrant due to signal spatial heterogeneity, and with reference to the other arterial wall segments in adjacent or contralateral arteries, then the post-injection signal was deemed nonenhancing. Concurrence of two readers was achieved in blinded interpretations.

\section{Monocyte protein preparation, JNK assays, and oxysterol determinations}

Human monocytes were isolated using a negative selection technique employing a RosetteSep Human Monocyte Enrichment Cocktail (StemCell Technologies \#15028), exactly as described by the manufacturer. Cells were lysed using a buffer containing $1 \%$ Tween 20 and $0.2 \%$ NP40 with protease and phosphatase inhibitors, and lysates were aliquoted and stored at $-80^{\circ} \mathrm{C}$.

Total and phospho (Thr183/Tyr185) JNK were assayed using chemiluminescent sandwich ELISA kits (Cell Signaling Technologies \#7869S and \#7849S). Extracts from subjects before and 1 year following treatment were analyzed in the same assay by an observer masked to randomization status. Signals detected from $1 \mu \mathrm{g}$ lysate protein (assayed with BCA reagents from Pierce) were determined using a Synergy 4 plate reader and the ratio of phospho-JNK to total JNK was calculated. For assays of cholestane- $3 \beta, 5 \alpha, 6 \beta$-triol, plasma samples stored at $-80{ }^{\circ} \mathrm{C}$ were thawed and combined with BHT $(50 \mu \mathrm{g} /$ $\mathrm{mL}$ ). Oxysterols were purified, derivatized, then quantified by GC-MS $(m / z 456)$ in assays performed within the linear response range of appropriate standard curves [20].

\section{Statistical analyses}

Results are expressed as mean $\pm \mathrm{SD}$ except in Fig. 2 where results are presented as mean $\pm S E$ to simplify data presentation. Statistical analyses were performed using GraphPad Prism software. For the dose escalation study, most data were analyzed using repeated measures ANOVA with post hoc testing using Tukey's multiple comparison test for inter-group differences. For the yearlong treatment study, most data were analyzed using a mixed model approach for repeated measures to allow for dealing with missing values. P values for mixed model analyses represent an assessment of whether the dependent variable was affected by the randomization group (placebo vs. chloroquine) vs. time interaction. Some analyses in both trials involving only two groups were performed using a two-tailed Student's t test. Spearman correlation coefficients were calculated for the relationships between baseline CIMT in the 116 randomized subjects and variables associated with atherosclerosis. Two-tailed paired t tests were used to analyze the baseline vs. 12-month results for MRI imaging and JNK activation. Binary baseline characteristics and adverse events were analyzed using contingency tables and Chi Square Test or Fisher's Exact Test.

\section{Results}

Metabolic effects of increasing doses of chloroquine

Characteristics for those completing the dose escalation study are shown in Table 1 . The primary endpoint of the first trial was clamp-determined insulin sensitivity. Twostage hyperinsulinemic euglycemic clamps were initially performed using insulin at 181 and $486 \mathrm{pmol} / \mathrm{m}^{2} / \mathrm{min}$. However, data analysis after the first seven patients demonstrated complete suppression of glucose production at the higher dose and nearly complete suppression at the lower dose, decreasing the ability to detect differences in endogenous glucose production in this group of patients with metabolic syndrome but not diabetes. Subsequent two-stage clamps were performed using insulin infusions at 56 and $181 \mathrm{pmol} / \mathrm{m}^{2} / \mathrm{min}$. The results from these first seven patients are included in Fig. 2b, c; the $486 \mathrm{pmol} /$ $\mathrm{m}^{2} / \mathrm{min}$ condition represents data points from these first patients for each limb while the $181 \mathrm{pmol} / \mathrm{m}^{2} / \mathrm{min}$ condition includes data points from these patients in addition to those from those undergoing clamps at 56 and $181 \mathrm{pmol} / \mathrm{m}^{2} / \mathrm{min}$. There were no differences in glucose

\section{Table 1 Baseline characteristics of subjects in the dose escalation study}

\begin{tabular}{ll}
\hline Variable & Results \\
\hline Number & 25 \\
Gender (F/M) & $18 / 7$ \\
Race & \\
Black & 2 \\
Non-hispanic white & 23 \\
Weight (kg) & $101 \pm 17$ \\
BMI (kg/m ${ }^{2}$ ) & $35.0 \pm 4.4$ \\
Waist circumference (cm) & $109 \pm 13$ \\
Fasting glucose (mmol/L) & $5.27 \pm 0.61$ \\
Systolic blood pressure (mmHg) & $135 \pm 16$ \\
Diastolic blood pressure (mmHg) & $80 \pm 10$ \\
Total cholesterol (mmol/L) & $5.25 \pm 0.67$ \\
Non-HDL cholesterol (mmol/L) & $4.11 \pm 0.62$ \\
LDL cholesterol (mmol/L) & $3.23 \pm 0.57$ \\
Triglycerides (mmol/L) & $1.85 \pm 0.61$ \\
HDL cholesterol (mmol/L) & $1.19 \pm 0.26$ \\
\hline
\end{tabular}

Data represent mean $\pm S D$ 
disposal rates between any of the chloroquine doses as shown in Fig. 2b.

There was a dose-dependent effect of chloroquine on hepatic glucose production (clamp-determined rate of appearance) with significant suppression at doses of $80 \mathrm{mg} /$ day and $250 \mathrm{mg} /$ day as determined by repeated measures ANOVA (Fig. 2c). Figure $2 \mathrm{~d}$ shows that chloroquine increased hepatic insulin sensitivity based on data from the $56 \mathrm{pmol} / \mathrm{m}^{2} / \mathrm{min}$ stage.

There was also an apparent dose-dependent effect of chloroquine on fasting levels of total cholesterol, nonHDL cholesterol, and LDL cholesterol with a significant decrease at 250/day as determined by repeated measures ANOVA (Fig. 2e). Serum triglycerides and HDL cholesterol were unchanged (Fig. 2f).

Chloroquine in this dose escalation study had no effect on blood pressure determined using an ambulatory monitor as shown in Table 2. SBP, DBP, MAP, and magnitude of BP decrease overnight ("dipping" status) were unaffected in all limbs. Consistent with an effect of chloroquine on hepatic insulin sensitivity, fasting glucose at the time of the clamp was significantly decreased (Table 2). Consistent with the lack an effect of chloroquine on glucose disposal, OGTT AUC results were unaffected in all limbs (Table 2). There was also no effect on body weight, glucagon, leptin, NEFA, C-peptide or insulin (Table 2).

There was a trend toward lower levels of TNFa (Table 2), but other inflammatory markers including CRP and adiponectin were unaffected (Table 2), consistent with other large studies of the relationship between this adipokine and insulin sensitivity [21].

Iron is linked to the development of diabetes [22] and ferritin is the major storage form of iron. Chloroquine treatment was associated with a significant decrease in ferritin levels in humans (Table 2), confirming an effect seen in rodents [23].

Table 2 Dose effect of chloroquine on blood pressure and other variables

\begin{tabular}{|c|c|c|c|c|c|}
\hline Variable & Placebo & $80 \mathrm{mg} /$ week & 80 mg/day & 250 mg/day & $P$ value \\
\hline $\mathrm{SBP}(\mathrm{mmHg})$ & $121 \pm 12$ & $121 \pm 10$ & $123 \pm 12$ & $123 \pm 12$ & 0.5607 \\
\hline $\mathrm{DBP}(\mathrm{mmHg})$ & $70 \pm 7$ & $71 \pm 7$ & $73 \pm 8$ & $73 \pm 9$ & 0.1107 \\
\hline MAP $(\mathrm{mmHg})$ & $87 \pm 8$ & $88 \pm 7$ & $89 \pm 9$ & $90 \pm 9$ & 0.1944 \\
\hline Overnight MAP dip & $8.8 \pm 4.2$ & $9.5 \pm 5.3$ & $9.5 \pm 8.8$ & $9.6 \pm 5.0$ & 0.9878 \\
\hline Fasting glucose clamp & $5.77 \pm 0.53$ & $5.83 \pm 0.52$ & $5.83 \pm 0.53$ & $5.44 \pm 0.65$ & $0.0010^{*}$ \\
\hline Fasting glucose OGTT & $5.49 \pm 0.57$ & $5.77 \pm 0.56$ & $5.72 \pm 0.62$ & $5.66 \pm 0.62$ & 0.0805 \\
\hline OGTT AUC (mmol/L/h) & $16.93 \pm 3.05$ & $17.65 \pm 3.00$ & $17.87 \pm 3.22$ & $17.26 \pm 3.61$ & 0.3585 \\
\hline Weight (kg) & $104 \pm 18$ & $103 \pm 18$ & $104 \pm 19$ & $103 \pm 19$ & 0.6041 \\
\hline $\mathrm{BMI}$ & $35.9 \pm 4.3$ & $35.9 \pm 4.2$ & $35.9 \pm 4.5$ & $35.5 \pm 4.6$ & 0.5964 \\
\hline Alc $(\%)$ & $5.8 \pm 0.4$ & ND & ND & $5.8 \pm 0.4$ & 0.9493 \\
\hline Insulin (pmol/L) & $153 \pm 94$ & $138 \pm 62$ & $166 \pm 107$ & $148 \pm 80$ & 0.4260 \\
\hline C peptide (nmol/L) & $1.16 \pm 0.44$ & $1.20 \pm 0.38$ & $1.26 \pm 0.44$ & $1.25 \pm 0.36$ & 0.5473 \\
\hline Glucagon (pg/mL) & $110 \pm 41$ & $101 \pm 26$ & $111 \pm 54$ & $102 \pm 50$ & 0.3646 \\
\hline Leptin ( $\mu \mathrm{g} / \mathrm{L})$ & $27.5 \pm 11.6$ & $27.2 \pm 11.1$ & $31.0 \pm 16.4$ & $27.2 \pm 11.9$ & 0.2134 \\
\hline NEFA (mmol/L) & $0.56 \pm 0.15$ & $0.55 \pm 0.10$ & $0.58 \pm 0.19$ & $0.55 \pm 0.16$ & 0.8776 \\
\hline $\mathrm{TNFa}(\mathrm{pg} / \mathrm{mL})$ & $12.9 \pm 1.8$ & $13.0 \pm 1.7$ & $12.2 \pm 1.9$ & $12.4 \pm 2.0$ & 0.0890 \\
\hline Fibrinogen ( $\mu \mathrm{mol} / \mathrm{L})$ & $8.44 \pm 1.32$ & $8.38 \pm 1.47$ & $8.14 \pm 1.09$ & $7.94 \pm 1.44$ & 0.3563 \\
\hline IL-6 (pg/mL) & $1.0 \pm 1.6$ & $1.4 \pm 1.5$ & $1.2 \pm 1.6$ & $0.96 \pm 1.3$ & 0.4282 \\
\hline $\mathrm{Lp}(\mathrm{a})(\mathrm{mg} / \mathrm{dL})$ & $22.9 \pm 17.5$ & $20.9 \pm 16.0$ & $22.5 \pm 17.2$ & $22.8 \pm 18.1$ & 0.1454 \\
\hline $\mathrm{CRP}(\mathrm{mg} / \mathrm{L})$ & $8.3 \pm 10.8$ & $7.9 \pm 10.6$ & $6.4 \pm 7.2$ & $7.5 \pm 8.0$ & 0.7455 \\
\hline Adiponectin $(\mu \mathrm{g} / \mathrm{mL})$ & $21.6 \pm 8.1$ & ND & ND & $20.6 \pm 5.6$ & 0.3503 \\
\hline Iron ( $\mu \mathrm{mol} / \mathrm{L})$ & $12.3 \pm 4.1$ & ND & ND & $11.4 \pm 5.5$ & 0.5311 \\
\hline Iron Bind. Cap. ( $\mu \mathrm{mol} / \mathrm{L})$ & $64.9 \pm 8.7$ & ND & ND & $65.8 \pm 10.0$ & 0.6385 \\
\hline Transferrin (mg/dL) & $300.3 \pm 47.5$ & ND & ND & $303.8 \pm 48.5$ & 0.6899 \\
\hline Transferrin Sat. (\%) & $19.1 \pm 6.4$ & ND & ND & $17.2 \pm 6.9$ & 0.3413 \\
\hline Ferritin (pmol/L) & $170 \pm 191$ & ND & ND & $105 \pm 88$ & $0.0155^{*}$ \\
\hline
\end{tabular}

Data represent mean $\pm S D$

MAP mean arterial pressure, NEFA non-esterified fatty acids, ND not determined

$P$ values determined by repeated measures ANOVA except for A1c, adiponectin, and iron studies, where $P$ value determined by paired $t$ test 


\section{Vascular effects of chloroquine treatment}

Baseline characteristics for the 107 subjects who completed the second trial, a double-blind placebo controlled study are shown in Table 3. The primary endpoint of the second trial was CIMT. To validate carotid measurements in this study cohort, baseline CIMT values for the 116 subjects randomized to chloroquine or placebo were correlated with common variables associated with atherosclerosis. CIMT was positively correlated with age $\left(r_{s}=0.3963, P<0.0001\right)$, systolic blood pressure $\left(r_{\mathrm{s}}=0.3379, \mathrm{P}=0.0002\right)$, triglycerides $\left(\mathrm{r}_{\mathrm{s}}=0.2936\right.$, $\mathrm{P}=0.0014)$, cholesterol $\left(\mathrm{r}_{\mathrm{s}}=0.3593, \mathrm{P}<0.0001\right)$, and LDL-C $\left(r_{s}=0.2590, P=0.0050\right)$. There were no correlations with HDL-C, diastolic blood pressure, waist circumference, BMI, glucose, TNF $\alpha$, IL-6, VEGF, or IL-17A (not shown).

There was no effect of chloroquine on CIMT after 12 months (Fig. 4b). Because chloroquine has a long half-life, imaging was repeated at 24 months, following a 12 -month washout period. These results also showed no difference between groups. MRI studies were performed only at baseline and at 12 months. Chloroquine did not affect contrast enhancement, a pre-specified secondary

Table 3 Baseline characteristics of subjects in the doubleblind study

\begin{tabular}{llll}
\hline Variable & Chloroquine group & Placebo group & P value \\
\hline Gender (F/M) & $44 / 12$ & $33 / 18$ & 0.1108 \\
Age & $55 \pm 12$ & $55 \pm 9$ & 0.9999 \\
Race (AA/NHW/H/NA) & $9 / 45 / 1 / 1$ & $6 / 45 / 0 / 0$ & 0.4990 \\
Smoking status & & & \\
$\quad$ Current & 8 & 10 & 0.4341 \\
Past & 21 & 23 & 0.2962 \\
Statin treatment & 15 & 15 & 0.8310 \\
Hypertension treat- & 20 & 19 & 0.9999 \\
$\quad$ ment & & & \\
Fish oil treatment & 5 & 10 & 0.1632 \\
Waist circumference & $110.4 \pm 10.5$ & $108.9 \pm 11.8$ & 0.6538 \\
BMI & $36.2 \pm 5.0$ & $34.2 \pm 5.0$ & $0.0433^{*}$ \\
SBP & & & \\
Screen & $137.1 \pm 14.3$ & $140.2 \pm 13.2$ & 0.2385 \\
Randomization & $129.2 \pm 11.4$ & $134.0 \pm 10.1$ & $0.0237^{*}$ \\
DBP & & & \\
Screen & $82.8 \pm 9.5$ & $83.0 \pm 9.7$ & 0.9483 \\
Randomization & $78.3 \pm 7.4$ & $79.7 \pm 7.2$ & 0.3244 \\
Glucose & $5.48 \pm 0.53$ & $5.52 \pm 0.64$ & 0.6960 \\
Triglycerides & $1.84 \pm 1.04$ & $1.82 \pm 0.93$ & 0.9155 \\
HDL-C & $1.14 \pm 0.26$ & $1.14 \pm 0.27$ & 0.9603 \\
Cholesterol & $5.00 \pm 0.85$ & $5.18 \pm 1.15$ & 0.3834 \\
LDL-C & $3.04 \pm 0.68$ & $3.28 \pm 0.82$ & 0.1073 \\
\hline Dateprent & &
\end{tabular}

Data represent mean \pm SD endpoint of the study (Fig. 4c, $\mathrm{P}=0.0697$, paired twotailed $t$ test). Representative images of vessels at baseline and 12 months are shown in Fig. 4d. Carotid dimensions were also assessed by MRI. Chloroquine was associated with a decrease in common carotid artery luminal area (Fig. 4e, $\mathrm{P}=0.0033$ ) and diameter (Fig. 4f, $\mathrm{P}=0.0019$ ).

\section{Effects of chloroquine on blood pressure, lipids, and other variables}

Drug treatment over the first year was associated with a significantly lower diastolic blood pressure $(\mathrm{P}=0.0252$ at 12 months), results that were driven by a $4.9 \mathrm{~mm} \mathrm{Hg}$ decrease at the 6 month time point (Fig. 5a). Ambulatory monitoring results (performed at baseline, 6 months, and 12 months but not at 24 months) were consistent with a beneficial effect of chloroquine on blood pressure. Drug treatment over the first year was associated with significantly lower daytime mean arterial pressure (Fig. 5b, $\mathrm{P}=0.0484)$. Daytime $(\mathrm{P}=0.0804)$ and nighttime $(\mathrm{P}=0.0659)$ systolic pressures by ambulatory monitoring were not different (Fig. $5 \mathrm{c}, \mathrm{d}$ ). By mixed model testing for the interaction between group and time, there was no effect of chronic chloroquine on lipids. However, at 12 months, a pre-specified secondary endpoint, total cholesterol was $9 \%$ lower (Fig. 5e, $\mathrm{P}=0.0089$ by unpaired $\mathrm{t}$ test), non-HDL cholesterol was $12 \%$ lower (Fig. $5 f, \mathrm{P}=0.0048$ by unpaired $\mathrm{t}$ test), and LDL-C was $13 \%$ lower (Fig. $5 \mathrm{~g}, \mathrm{P}=0.0038$ by unpaired $\mathrm{t}$ test) in the chloroquine group. Glucose area under the curve (AUC) as well as HOMA-IR and the Matsuda index, measures of insulin sensitivity [24], were not different between groups (Table 4). There was no effect of chloroquine on insulin AUC, C peptide AUC, or the insulinogenic index (the difference between insulin at $30 \mathrm{~min}$ and 0 min divided by the difference between glucose at $30 \mathrm{~min}$ and $0 \mathrm{~min}$ ) (Table 4), suggesting that chronic chloroquine treatment at this dose does not impact insulin levels in humans. Glucagon AUC, creatinine, ALT, and hematologic variables were not different between treatment groups (Table 4).

\section{Potential mechanistic mediators}

JNK is a stress kinase implicated in obesity-associated chronic inflammation [25]. JNK activation in monocytes, a pre-specified secondary endpoint, was significantly decreased in chloroquine-treated but not placebo-treated subjects (Fig. 6a). Reactive oxygen species activate JNK and have been implicated in the pathophysiology of obesity-associated conditions [26]. Plasma cholesterol oxidation products are elevated in diabetes and coronary artery disease [20]. Cholestane- $3 \beta, 5 \alpha, 6 \beta$-triol, one species that may reflect clinically relevant oxidative 

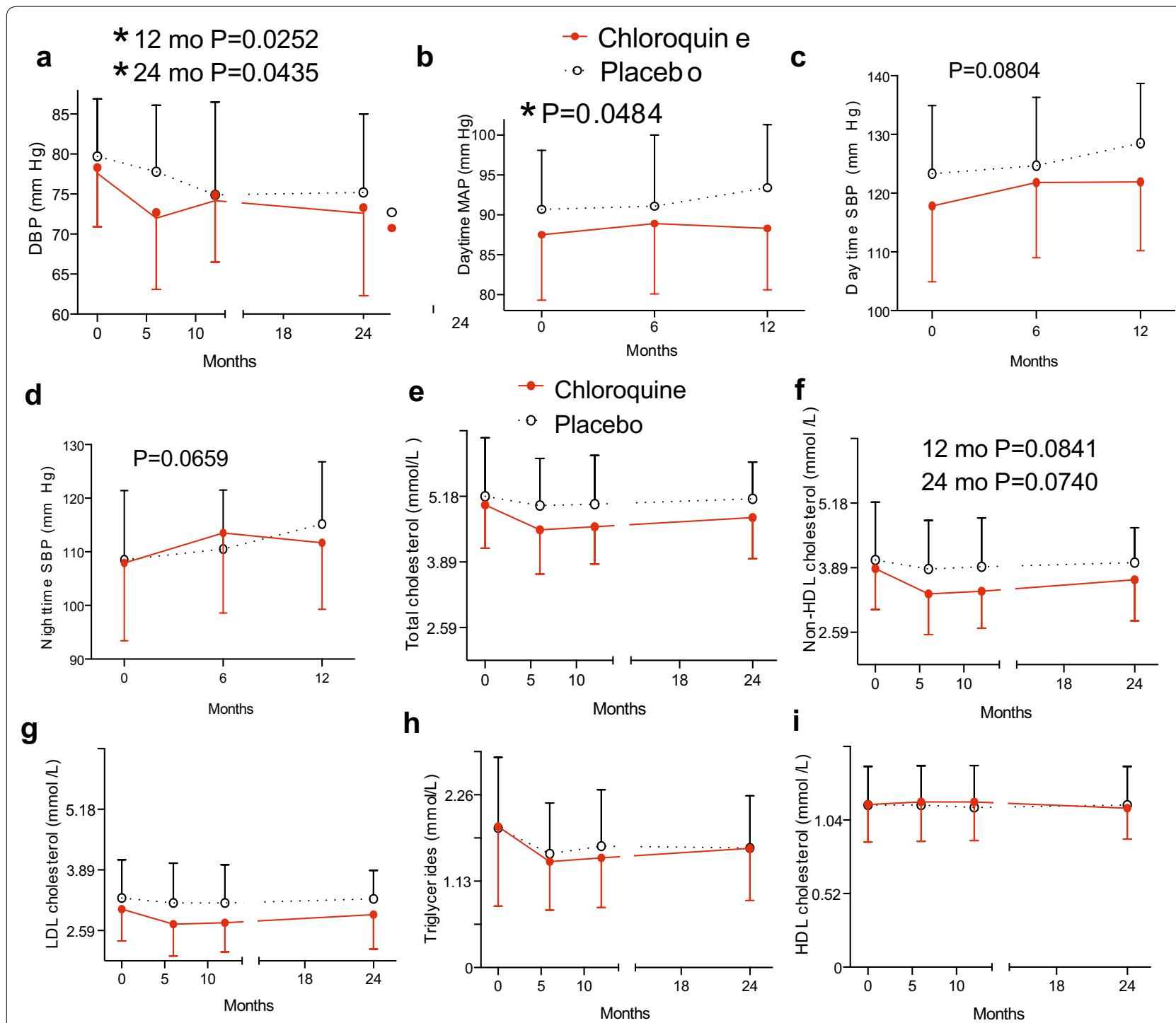

Fig. 5 Blood pressure and lipid responses in the yearlong chloroquine trial. a Diastolic blood pressure over 24 months determined by conventional testing. b-d Blood pressures over 12 months, determined by an ambulatory monitoring device. e-i Lipids and lipoproteins over 24 months. P values were determined by mixed model treatment of repeated measures

stress [20], was significantly decreased in the chloroquine group at 12 months (Fig. 6b).

\section{Adverse events}

For the dose escalation study, there were no serious adverse events (Table 5). Not unexpectedly given the rigors of a series of clamps, there were several study-related events. Of adverse events that were not directly studyrelated, infections were the most common.

For the double blind study, there were 7 serious events. In the placebo group, one subject presented with a new diagnosis of prostate cancer. One subject underwent a right knee replacement. In the chloroquine group, one patient developed transverse myelitis presenting with left leg weakness that subsequently improved but did not completely resolve. One subject underwent carotid endarterectomy for asymptomatic near-total carotid occlusion detected at 6 months. One subject was hospitalized for a cutaneous staphylococcus infection that resolved with appropriate therapy. One subject was treated for acute appendicitis, stopped the study medication for 1 week then resumed without incident. One subject was found to have a positive PPD without evidence of pulmonary tuberculosis.

Total adverse events were similar between groups (Table 6). There were more infectious events in those 
Table 4 Effects of chloroquine vs. placebo over 24 months (off either, i.e. washout, months 12-24)

\begin{tabular}{|c|c|c|c|c|c|}
\hline Variable & Baseline & 6 months & 12 months & 24 months & P value \\
\hline \multicolumn{6}{|l|}{ Waist (cm) } \\
\hline Chloroquine & $110.4 \pm 10.5$ & $112.5 \pm 12.6$ & $112.6 \pm 13.6$ & $113.2 \pm 16.6$ & \multirow[t]{2}{*}{$0.5578(12 \mathrm{~m})$} \\
\hline Placebo & $108.9 \pm 11.8$ & $110.4 \pm 13.8$ & $109.8 \pm 12.4$ & $108.9 \pm 15.9$ & \\
\hline \multicolumn{6}{|l|}{ Weight (kg) } \\
\hline Chloroquine & $102.9 \pm 16.7$ & $102.9 \pm 16.7$ & $103.1 \pm 19.2$ & $105.9 \pm 20.4$ & 0.1323 \\
\hline Placebo & $99.7 \pm 18.5$ & $98.7 \pm 18.5$ & $99.2 \pm 17.8$ & $100.5 \pm 21.2$ & 0.1909 (t test $24 \mathrm{~m}$ ) \\
\hline \multicolumn{6}{|l|}{ Fasting glucose } \\
\hline Chloroquine & $5.48 \pm 0.53$ & $5.36 \pm 0.55$ & $5.30 \pm 0.51$ & $5.58 \pm 0.73$ & $0.2741(12 \mathrm{~m})$ \\
\hline Placebo & $5.52 \pm 0.64$ & $5.52 \pm 0.62$ & $5.51 \pm 0.71$ & $5.63 \pm 0.74$ & 0.0930 (t test $12 \mathrm{~m}$ ) \\
\hline \multicolumn{6}{|l|}{ Glucose AUC } \\
\hline Chloroquine & $16.32 \pm 2.46$ & $15.94 \pm 2.24$ & $16.17 \pm 2.58$ & $16.97 \pm 3.20$ & \multirow[t]{2}{*}{0.2537} \\
\hline Placebo & $16.54 \pm 3.49$ & $16.87 \pm 3.29$ & $16.43 \pm 3.34$ & $17.50 \pm 3.85$ & \\
\hline \multicolumn{6}{|l|}{ Insulin AUC } \\
\hline Chloroquine & $1202 \pm 681$ & $1118 \pm 542$ & $1143 \pm 603$ & $1213 \pm 716$ & \multirow[t]{2}{*}{0.2479} \\
\hline Placebo & $1003 \pm 524$ & $1054 \pm 588$ & $995 \pm 570$ & $1022 \pm 613$ & \\
\hline \multicolumn{6}{|l|}{ C peptide AUC } \\
\hline Chloroquine & $7.46 \pm 2.33$ & $7.23 \pm 2.10$ & $7.16 \pm 2.20$ & $7.39 \pm 2.43$ & \multirow[t]{2}{*}{0.2918} \\
\hline Placebo & $6.49 \pm 1.80$ & $6.69 \pm 2.06$ & $6.46 \pm 2.00$ & $6.79 \pm 2.06$ & \\
\hline \multicolumn{6}{|l|}{ HOMA-IR } \\
\hline Chloroquine & $3.89 \pm 2.23$ & $3.85 \pm 2.21$ & $3.57 \pm 2.12$ & $3.72 \pm 3.53$ & \multirow[t]{2}{*}{0.8421} \\
\hline Placebo & $3.54 \pm 2.03$ & $3.64 \pm 2.08$ & $3.30 \pm 2.23$ & $3.29 \pm 2.26$ & \\
\hline \multicolumn{6}{|l|}{ Matsuda index } \\
\hline Chloroquine & $2.89 \pm 1.72$ & $2.88 \pm 1.55$ & $3.13 \pm 2.31$ & $3.43 \pm 2.84$ & \multirow[t]{2}{*}{0.8997} \\
\hline Placebo & $3.21 \pm 1.89$ & $3.07 \pm 1.64$ & $3.50 \pm 2.14$ & $3.56 \pm 2.70$ & \\
\hline \multicolumn{6}{|c|}{ Insulinogenic index } \\
\hline Chloroquine & $1.40 \pm 1.75$ & $1.17 \pm 0.87$ & $1.24 \pm 0.87$ & $1.12 \pm 0.89$ & \multirow[t]{2}{*}{0.4988} \\
\hline Placebo & $1.05 \pm 0.77$ & $1.03 \pm 0.67$ & $1.09 \pm 0.88$ & $1.13 \pm 1.62$ & \\
\hline \multicolumn{6}{|l|}{ Glucagon AUC } \\
\hline Chloroquine & $174.0 \pm 63.5$ & $152.3 \pm 60.3$ & $126.8 \pm 43.3$ & ND & \multirow[t]{2}{*}{0.6126} \\
\hline Placebo & $168.0 \pm 60.6$ & $138.7 \pm 46.7$ & $119.8 \pm 36.2$ & ND & \\
\hline \multicolumn{6}{|c|}{ Creatinine ( $\mu \mathrm{mol} / \mathrm{L})$} \\
\hline Chloroquine & $68 \pm 14$ & $67 \pm 15$ & $66 \pm 15$ & ND & \multirow[t]{2}{*}{0.7859} \\
\hline Placebo & $66 \pm 16$ & $65 \pm 17$ & $65 \pm 17$ & & \\
\hline \multicolumn{6}{|l|}{ ALT } \\
\hline Chloroquine & $26 \pm 16$ & $26 \pm 19$ & $26 \pm 15$ & ND & \multirow[t]{2}{*}{0.2056} \\
\hline Placebo & $25 \pm 12$ & $27 \pm 16$ & $23 \pm 9$ & ND & \\
\hline \multicolumn{6}{|l|}{ WBC count } \\
\hline Chloroquine & $6.7 \pm 1.8$ & $6.3 \pm 1.6$ & $6.0 \pm 1.5$ & ND & \multirow[t]{2}{*}{0.7249} \\
\hline Placebo & $6.5 \pm 1.7$ & $6.3 \pm 1.8$ & $6.1 \pm 1.9$ & ND & \\
\hline \multicolumn{6}{|l|}{ Hemoglobin } \\
\hline Chloroquine & $13.6 \pm 1.1$ & $13.3 \pm 1.1$ & $13.2 \pm 1.2$ & ND & 0.8953 \\
\hline Placebo & $13.8 \pm 0.8$ & $13.5 \pm 0.9$ & $13.5 \pm 0.9$ & ND & \\
\hline
\end{tabular}

Data represent mean $\pm S D$

$P$ values determined by mixed model approach to repeated measures except where indicated

randomized to chloroquine but this was not significant (51 vs. $42, \mathrm{P}=0.0609$ ). No subject in either study developed retinal pigmentary changes that may occur with chloroquine. For the double blind study, observers masked to the treatment assignment examined each subject at $0,6,12$, and 24 months. Ocular adverse events were not significantly different between treatment groups (Table 6). 

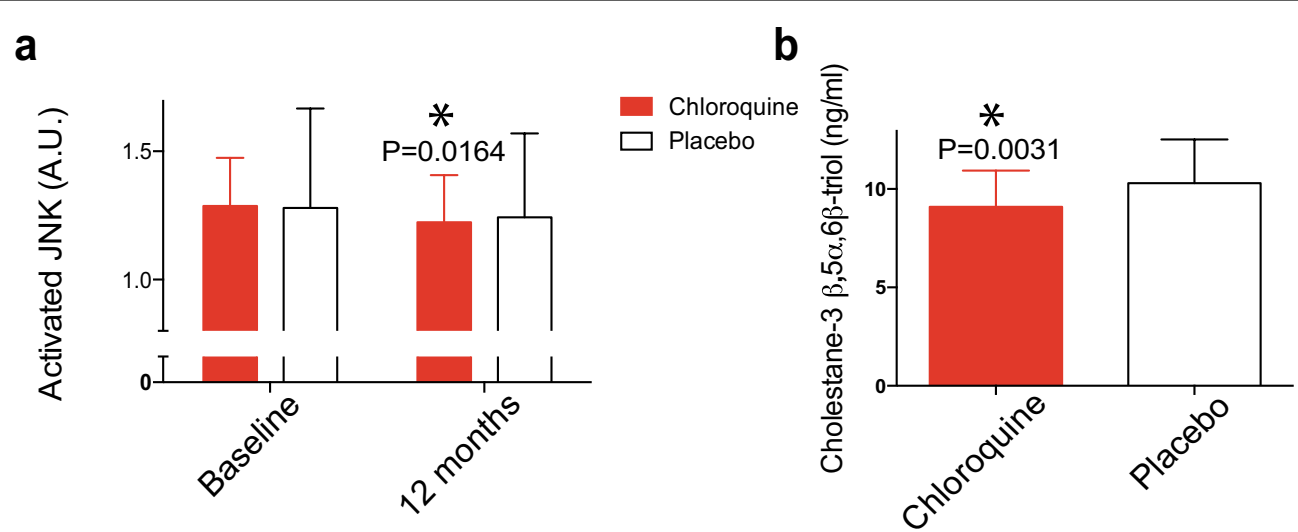

Fig. 6 Effects of placebo and chloroquine on potential mechanistic mediators. a Activated JNK in circulating monocytes at baseline and 12 months. ${ }^{*} \mathrm{P}=0.0164 ; \mathrm{P}=0.3343$ for placebo; paired t tests. $\mathbf{b}$ Plasma concentrations of the oxysterol cholestane- $3 \beta, 5 \mathrm{a}, 6 \beta$-triol at 12 months. ${ }^{*} \mathrm{P}=0.0031$; unpaired t test

Table 5 Adverse events in the dose escalation study

\begin{tabular}{lc}
\hline Adverse event & Subjects (\%) \\
\hline Total subjects with any event & $24(69)$ \\
Subjects with a serious adverse event & $0(0)$ \\
Total adverse events & $57(100)$ \\
Study related & $14(25)$ \\
IV placement difficulties & $1(1.8)$ \\
IV infiltration & $1(1.8)$ \\
Phlebitis & $1(1.8)$ \\
Skin reaction to tape & $1(1.8)$ \\
Extremity erythema due to BP cuff & $1(1.8)$ \\
Vasovagal episode with IV placement & $1(1.8)$ \\
Incorrect stable isotope administered & $1(1.8)$ \\
Nausea & $3(5)$ \\
Anemia & $4(7)$ \\
Not study related & $43(75)$ \\
Infectious & $15(26)$ \\
Allergy/immunology & $3(5)$ \\
Musculoskeletal & $8(14)$ \\
CNS & $3(5)$ \\
Psychiatric & $5(9)$ \\
Cardiovascular & $2(4)$ \\
Gl & $4(7)$ \\
Metabolic & $3(5)$ \\
\hline Parthen &
\end{tabular}

Parentheses denote \%

\section{Discussion}

We tested the hypothesis that the anti-malarial drug chloroquine, which activates the kinase ATM, improves insulin sensitivity and decreases atherosclerosis in humans with metabolic syndrome. In mice, low dose chloroquine improves insulin sensitivity, decreases atherosclerosis, and suppresses activation of JNK in macrophages through pathways that require the presence of ATM [6]. The absence of ATM in mice affects hepatic insulin sensitivity and promotes atherosclerosis, suggesting the involvement of processes that link hepatic insulin resistance and vascular disease. Accordingly, we translated these findings to humans by conducting two trials, the first to determine if chloroquine improves insulin sensitivity in the liver, and the second to determine if chloroquine decreases CIMT.

The overall results were disappointing. Hyperinsulinemic euglycemic clamp studies demonstrated a dose response relationship between chloroquine administration and hepatic insulin sensitization but the effect was modest. Treatment with chloroquine for 1 year (using the lowest dose found to increase hepatic insulin sensitivity) had no effect on the primary endpoint of CIMT and no beneficial effects on MRI imaging. One limitation of the study is that it may have been underpowered to detect a difference in CIMT. Sample size estimates at the time of initiation of these studies were based on reports showing that insulin sensitizers had effects on CIMT with groups of 31-57 subjects [27-30], but subsequent work indicated the need for larger sample sizes [31]. Taken together, our findings suggest that chloroquine will not be clinically useful for the treatment of metabolic syndrome.

There were positive results from our studies. Chronic administration of chloroquine lowered blood pressure, decreased activation of JNK in circulating monocytes, and decreased concentration of a cholesterol oxidation product that reflects oxidative stress. These findings suggest that chloroquine decreases systemic inflammation and improves some components of the metabolic 
Table 6 Adverse events in the double-blind study

\begin{tabular}{llll}
\hline Adverse event & Chloroquine subjects (\%) & Placebo subjects (\%) & P value \\
\hline Total subjects with any event & $44(76)$ & $39(67)$ & 0.4107 \\
Subjects with a serious adverse event & $5(9)$ & $2(3)$ & 0.4385 \\
Total adverse events & $109(100)$ & $42(40)$ & - \\
Infectious & $51(47)$ & $10(10)$ & 0.0609 \\
Allergy/immunology & $5(5)$ & $15(15)$ & 0.2681 \\
Musculoskeletal & $17(16)$ & $3(3)$ & 0.8357 \\
CNS & $5(5)$ & $6(6)$ & - \\
Psychiatric & $5(5)$ & $2(2)$ & - \\
Hematologic/neoplasm & $2(2)$ & $3(3)$ & - \\
Cardiovascular & $2(2)$ & $3(3)$ & - \\
Gl & $3(3)$ & $2(2)$ & - \\
GU & $2(2)$ & $6(6)$ & - \\
Metabolic & $1(1)$ & $3(3)$ & - \\
Miscellaneous & $0(0)$ & $10(10)$ & - \\
Ocular & $16(15)$ & & - \\
Ocular details & & 3 & - \\
Retinal & 3 & 2 & 0
\end{tabular}

Parentheses denote \%

$P$ values determined using contingency tables

syndrome. The inhibition of JNK is known to enhance insulin sensitivity and decrease atherosclerosis in animals [32,33]. Oxidative stress activates JNK, and recent studies implicate ATM, which is activated by chloroquine, in modulation of reactive oxygen species generation [34]. Metformin, the most widely used insulin sensitizer, appears to work through redox-dependent mechanisms in liver [35]. Variants in the ATM gene alter the glycemic response to metformin in humans [36]. These findings raise the possibility that chloroquine induction of ATM activity modifies redox signaling to decrease insulin resistance, but in humans these effects are small.

Hydroxychloroquine, closely related to chloroquine, improves glycemic control in poorly controlled type 2 diabetes in humans [37] and may improve glucose metabolism in human prediabetes [38]. Its use in rheumatoid arthritis is associated with a reduced risk for developing diabetes in large observational studies [39, 40], and its administration to healthy obese subjects without the metabolic syndrome increases the Matsuda index of insulin sensitivity [41].

Chloroquine was well tolerated. Subjects in the dose escalation study received $7.2 \mathrm{~g}$ and those in the yearlong study $29.2 \mathrm{~g}$. Retinopathy is a serious but rare adverse effect of chloroquine; our subjects had regular eye exams and retinopathy was not detected.

\section{Conclusions}

Low dose chloroquine modestly enhanced hepatic insulin sensitivity but did not affect CIMT. Despite some positive effects on secondary endpoints including the demonstration of suppression of the stress kinase JNK, overall results suggest that chloroquine will not be useful for the treatment of metabolic syndrome in humans.

\section{Abbreviations}

ALT: alanine aminotransferase; ANOVA: analysis of variance; AUC: area under the curve; ATM: ataxia telangiectasia mutated; BMI: body mass index; CIMT: carotid intima-media thickness; CLIA: Clinical Laboratory Improvement Amendments; COPD: chronic obstructive pulmonary disease; CRP: C-reactive protein; DBP: diastolic blood pressure; DNA: deoxyribonucleic acid; G6PD: glucose-6-phosphate dehydrogenase; HDL: high density lipoprotein; HIV: human immunodeficiency virus; HOMA-IR: homeostasis model assessmentinsulin resistance; IL-6: interleukin 6; IL-17A: interleukin 17A; IV: intravenous: JNK: C-Jun-N-terminal kinase; LDL: low density lipoprotein; LDL-C: low density lipoprotein cholesterol; MAP: mean arterial pressure; MRI: magnetic resonance imaging; NEFA: non-esterified fatty acid; NHLBI: National Heart, Lung, and Blood Institute; OGTT: oral glucose tolerance test; SBP: systolic blood pressure; SD: standard deviation; SE: standard error; TNFa: tumor necrosis factor alpha; VEGF: vascular endothelial growth factor. 


\section{Acknowledgements}

We appreciate the efforts of the dedicated volunteers who devoted considerable time to participate in these trials, and the suggestions of the members of the data safety and monitoring board.

\section{Authors' contributions}

CFS obtained the funding; JBM, MJ, SH, WTC and CFS conducted the clinical trial; WTC, KEY, REO, BR, MBK, DAM, DSO and CFS analyzed samples; LLF and VGD conducted the CIMT studies; SAW conducted the MRI studies, CFS and KBS analyzed the data. CFS wrote the manuscript; JBM edited the manuscript. All authors read and approved the final manuscript.

\section{Funding}

This work was supported by NIH Grants HL083762, DK020579, DK076729, DK056341, GM103422, UL1RR024992, KL2RR024994.

\section{Availability of data and materials}

The datasets used and analyzed in the current study are available from the corresponding authors on reasonable request. All data generated during this study are included in this published article.

\section{Ethics approval and consent to participate}

Ethics approval was granted by the Washington University Human Research Protection Office, Washington University in St. Louis, St. Louis, Missouri. All patients provided written informed consent.

\section{Consent for publication}

Not applicable.

\section{Competing interests}

The authors declare that they have no competing interests.

\section{Author details}

${ }^{1}$ Division of Endocrinology, Metabolism \& Lipid Research, Department of Medicine, Washington University School of Medicine, 660 South Euclid Avenue, Box 8127, St. Louis, MO 63110, USA. ${ }^{2}$ Program in Physical Therapy, Washington University, St. Louis, MO, USA. ${ }^{3}$ Division of Biostatistics, Washington University, St. Louis, MO, USA. ${ }^{4}$ Cardiovascular Division, Washington University, St. Louis, MO, USA. ${ }^{5}$ Department of Pharmacology \& Cancer Biology, Duke University, Durham, NC, USA. ${ }^{6}$ Department of Internal Medicine, Wake Forest School of Medicine, Winston-Salem, NC, USA. ${ }^{7}$ Department of Cell Biology \& Physiology, Washington University, St. Louis, MO, USA.

Received: 5 April 2019 Accepted: 20 July 2019

Published online: 29 July 2019

\section{References}

1. Eckel RH, Alberti KG, Grundy SM, Zimmet PZ. The metabolic syndrome. Lancet. 2010;375(9710):181-3

2. Mottillo S, Filion KB, Genest J, Joseph L, Pilote L, Poirier P, et al. The metabolic syndrome and cardiovascular risk a systematic review and meta-analysis. JACC. 2010;56(14):1113-32.

3. Solinas G, Becattini B. JNK at the crossroad of obesity, insulin resistance, and cell stress response. Mol Metab. 2017;6(2):174-84.

4. Look ARG, Gregg EW, Jakicic JM, Blackburn G, Bloomquist P, Bray GA, et al. Association of the magnitude of weight loss and changes in physical fitness with long-term cardiovascular disease outcomes in overweight or obese people with type 2 diabetes: a post hoc analysis of the Look AHEAD randomised clinical trial. Lancet Diabetes Endocrinol. 2016;4(11):913-21.

5. Semenkovich CF. Insulin resistance and atherosclerosis. J Clin Invest. 2006;116(7):1813-22.

6. Schneider JG, Finck BN, Ren J, Standley KN, Takagi M, Maclean KH, et al. ATM-dependent suppression of stress signaling reduces vascular disease in metabolic syndrome. Cell Metab. 2006:4(5):377-89.

7. Mercer JR, Cheng KK, Figg N, Gorenne I, Mahmoudi M, Griffin J, et al. DNA damage links mitochondrial dysfunction to atherosclerosis and the metabolic syndrome. Circ Res. 2010;107(8):1021-31.
8. Le Guezennec X, Brichkina A, Huang YF, Kostromina E, Han W, Bulavin DV. Wip1-dependent regulation of autophagy, obesity, and atherosclerosis. Cell Metab. 2012;16(1):68-80.

9. Razani B, Feng C, Semenkovich CF. p53 is required for chloroquineinduced atheroprotection but not insulin sensitization. J Lipid Res. 2010;51(7):1738-46

10. Geisel MH, Bauer M, Hennig F, Hoffmann B, Lehmann N, Mohlenkamp $\mathrm{S}$, et al. Comparison of coronary artery calcification, carotid intimamedia thickness and ankle-brachial index for predicting 10-year incident cardiovascular events in the general population. Eur Heart J. 2017;38(23):1815-22

11. Subramanian S, DeRosa MA, Bernal-Mizrachi C, Laffely N, Cade WT, Yarasheski KE, et al. PPARalpha activation elevates blood pressure and does not correct glucocorticoid-induced insulin resistance in humans. Am J Physiol Endocrinol Metab. 2006;291(6):E1365-71.

12. Derosa G, Fogari E, D'Angelo A, Bianchi L, Bonaventura A, Romano D, et al. Adipocytokine levels in obese and non-obese subjects: an observational study. Inflammation. 2013;36(4):914-20.

13. Derosa G, Bonaventura A, Bianchi L, Romano D, Fogari E, et al. Effects of Berberis aristata/Silybum marianum association on metabolic parameters and adipocytokines in overweight dyslipidemic patients. J Biol Regul Homeost Agents. 2013;27(3):717-28.

14. Azimi-Nezhad M, Mirhafez SR, Stathopoulou MG, Murray H, Ndiaye NC, Bahrami A, et al. The relationship between vascular endothelial growth factor cis- and trans-acting genetic variants and metabolic syndrome. Am J Med Sci. 2018;355(6):559-65.

15. Suarez-Ortegon MF, Blanco E, McLachlan S, Fernandez-Real JM, Burrows R, Wild SH, et al. Ferritin levels throughout childhood and metabolic syndrome in adolescent stage. Nutr Metab Cardiovasc Dis. 2019;29(3):268-78.

16. Demir E, Harmankaya NO, Kirac Utku I, Aciksari G, Uygun T, Ozkan H, et al. The relationship between epicardial adipose tissue thickness and serum interleukin-17a level in patients with isolated metabolic syndrome. Biomolecules. 2019;9(3):97.

17. Gabrielsen JS, Gao Y, Simcox JA, Huang J, Thorup D, Jones D, et al. Adipocyte iron regulates adiponectin and insulin sensitivity. J Clin Invest. 2012;122(10):3529-40.

18. Stein JH, Korcarz CE, Hurst RT, Lonn E, Kendall CB, Mohler ER, et al. Use of carotid ultrasound to identify subclinical vascular disease and evaluate cardiovascular disease risk: a consensus statement from the American Society of Echocardiography Carotid Intima-Media Thickness Task Force. J Am Soc Echocardiography. 2008;21(2):93-111.

19. de Fuentes L, Waggoner AD, Mohammed BS, Stein RI, Miller BV 3rd, Foster $G D$, et al. Effect of moderate diet-induced weight loss and weight regain on cardiovascular structure and function. JACC. 2009;54(25):2376-81.

20. Porter FD, Scherrer DE, Lanier MH, Langmade SJ, Molugu V, Gale SE, et al. Cholesterol oxidation products are sensitive and specific blood-based biomarkers for Niemann-Pick C1 disease. Sci Transl Med. 2010;2(56):5681.

21. Yaghootkar H, Lamina C, Scott RA, Dastani Z, Hivert MF, Warren LL, et al. Mendelian randomization studies do not support a causal role for reduced circulating adiponectin levels in insulin resistance and type 2 diabetes. Diabetes. 2013;62(10):3589-98.

22. Simcox JA, McClain DA. Iron and diabetes risk. Cell Metab. 2013;17(3):329-41.

23. Ramm GA, Powell LW, Halliday JW. Pathways of intracellular trafficking and release of ferritin by the liver in vivo: the effect of chloroquine and cytochalasin D. Hepatology. 1994;19(2):504-13.

24. Matsuda M, DeFronzo RA. Insulin sensitivity indices obtained from oral glucose tolerance testing: comparison with the euglycemic insulin clamp. Diabetes Care. 1999;22(9):1462-70.

25. Han MS, Jung DY, Morel C, Lakhani SA, Kim JK, Flavell RA, et al. JNK expression by macrophages promotes obesity-induced insulin resistance and inflammation. Science. 2013;339(6116):218-22.

26. Houstis N, Rosen ED, Lander ES. Reactive oxygen species have a causal role in multiple forms of insulin resistance. Nature. 2006;440(7086):944-8.

27. Minamikawa J, Tanaka S, Yamauchi M, Inoue D, Koshiyama H. Potent inhibitory effect of troglitazone on carotid arterial wall thickness in type 2 diabetes. J Clin Endocrinol Metab. 1998:83(5):1818-20.

28. Koshiyama H, Shimono D, Kuwamura N, Minamikawa J, Nakamura Y. Rapid communication: inhibitory effect of pioglitazone on carotid 
arterial wall thickness in type 2 diabetes. J Clin Endocrinol Metab. 2001;86(7):3452-6.

29. Stocker DJ, Taylor AJ, Langley RW, Jezior MR, Vigersky RA. A randomized trial of the effects of rosiglitazone and metformin on inflammation and subclinical atherosclerosis in patients with type 2 diabetes. Am Heart J. 2007;153(3):445.

30. Xiang AH, Hodis HN, Kawakubo M, Peters RK, Kjos SL, Marroquin A, et al. Effect of pioglitazone on progression of subclinical atherosclerosis in non-diabetic premenopausal Hispanic women with prior gestational diabetes. Atherosclerosis. 2008;199(1):207-14.

31. Saremi A, Schwenke DC, Buchanan TA, Hodis HN, Mack WJ, Banerji $\mathrm{M}$, et al. Pioglitazone slows progression of atherosclerosis in prediabetes independent of changes in cardiovascular risk factors. ATVB. 2013;33(2):393-9.

32. Kaneto H, Nakatani Y, Miyatsuka T, Kawamori D, Matsuoka TA, Matsuhisa $\mathrm{M}$, et al. Possible novel therapy for diabetes with cell-permeable JNKinhibitory peptide. Nat Med. 2004;10(10):1128-32.

33. Ricci R, Sumara G, Sumara I, Rozenberg I, Kurrer M, Akhmedov A, et al. Requirement of JNK2 for scavenger receptor A-mediated foam cell formation in atherogenesis. Science. 2004;306(5701):1558-61.

34. Valentin-Vega YA, Maclean KH, Tait-Mulder J, Milasta S, Steeves M, Dorsey $\mathrm{FC}$, et al. Mitochondrial dysfunction in ataxia-telangiectasia. Blood. 2012;119(6):1490-500

35. Madiraju AK, Qiu Y, Perry RJ, Rahimi Y, Zhang XM, Zhang D, et al. Metformin inhibits gluconeogenesis via a redox-dependent mechanism in vivo. Nature Med. 2018;24(9):1384-94.
36. GoDarts, Group UDPS, Wellcome Trust Case Control C, Zhou K, Bellenguez C, Spencer CC, et al. Common variants near ATM are associated with glycemic response to metformin in type 2 diabetes. Nat Genetics. 2011;43(2):117-20.

37. Gerstein HC, Thorpe KE, Taylor DW, Haynes RB. The effectiveness of hydroxychloroquine in patients with type 2 diabetes mellitus who are refractory to sulfonylureas-a randomized trial. Diabetes Res Clin Prac. 2002;55(3):209-19.

38. Sheikhbahaie F, Amini M, Gharipour M, Aminoroaya A, Taheri N. The effect of hydroxychloroquine on glucose control and insulin resistance in the prediabetes condition. Adv Biomed Res. 2016;5:145.

39. Wasko MC, Hubert HB, Lingala VB, Elliott JR, Luggen ME, Fries JF, et al. Hydroxychloroquine and risk of diabetes in patients with rheumatoid arthritis. JAMA. 2007;298(2):187-93.

40. Solomon DH, Massarotti E, Garg R, Liu J, Canning C, Schneeweiss S. Association between disease-modifying antirheumatic drugs and diabetes risk in patients with rheumatoid arthritis and psoriasis. JAMA. 2011;305(24):2525-31.

41. Mercer E, Rekedal L, Garg R, Lu B, Massarotti EM, Solomon DH. Hydroxychloroquine improves insulin sensitivity in obese non-diabetic individuals. Arthritis Res Ther. 2012;14(3):R135.

\section{Publisher's Note}

Springer Nature remains neutral with regard to jurisdictional claims in published maps and institutional affiliations.
Ready to submit your research? Choose BMC and benefit from:

- fast, convenient online submission

- thorough peer review by experienced researchers in your field

- rapid publication on acceptance

- support for research data, including large and complex data types

- gold Open Access which fosters wider collaboration and increased citations

- maximum visibility for your research: over 100M website views per year

At BMC, research is always in progress.

Learn more biomedcentral.com/submissions 